\title{
Analysis of public library users' digital preservation practices
}

\author{
Andrea J. Copeland \\ 2011 \\ Journal of the American Society for Information Science and Technology \\ 62(7), 1288-1300
}

Andrea J. Copeland, PhD

School of Informatics \& Computing

Department of Library and Information Science

Indiana University

755 W Michigan Street, UL3100C

Indianapolis, IN 46202

(w) 317- 274-0114

(f) 317.278 .1807

ajapzon@iupui.edu

This is the accepted version of the following article: Copeland, A. J. (2011). Analysis of public library users' digital preservation practices. Journal of the American Society for Information Science and Technology, 62(7), 1288-1300, which has been published in final form at http://dx.doi.org/10.1002/asi.21553 
Title: Analysis of public library users’ digital preservation practices

\begin{abstract}
This research investigated preservation practices of personal digital information by public library users. This qualitative study used semi-structured interviews and two visual representation techniques, information source horizons and matrices, for data collection. The constant comparison method and descriptive statistics were used to analyze the data. A model emerged which describes the effects of social, cognitive, and affective influences on personal preservation decisions, as well as the effects of fading cognitive associations and technological advances, combined with information escalation over time. Because the preservation of personal digital information involves personal, social, and technological interactions, the integration of these factors is necessary for a viable solution to the digital preservation problem.
\end{abstract}

\title{
Introduction
}

Digital information is threatened by technology obsolescence and media instability. Users of digital information depend upon digital devices, computer hardware and/or software to view or hear the digital objects as changes or advances in computer or digital technology can render digital files unreadable or unusable (Chen, 2001). Libraries and other memory institutions are aware of the crisis in digital preservation and are taking steps to preserve our collective cultural heritage (Rothenberg, J., 1998; LeFurgy, 2005; Ross \& Hedstrom, 2005; Bradley, 2007). In contrast, Marshall’s (2006, 2008a, 2008b) research suggests that individual consumers are much less aware of the impermanent state of their digital possessions, or if they are aware, they feel disempowered to do anything about it. As a result, valuable representations 
of personal memories intended for future generations will be lost through ignorance and/or benign neglect (Yakel, 2004), and representations of family and social histories will be lost to what has been called the "digital dark ages" (Kuny, 1998).

Today many individuals amass large amounts of digital content because, like libraries, they have access to inexpensive and seemingly endless storage capability and to the highpowered computing needed to facilitate the creation and the downloading of digital content (Beagrie, 2005). However, the personal digital device environment offers limited support for content organization and preservation, so the likelihood that individuals will lose valuable representations of personal memories is very real (Jones, 2007). Lyman and Varian (2003) found that $93 \%$ of all new information is born digital and resides only on magnetic or optical storage devices the longevity of such information is the most threatened and in the most need of research and development.

Public library users were specifically chosen as the focus of this study because they are underserved in terms research and services related to digital preservation. Whereas, in corporate and academic library environments institutional repositories are being developed to meet the long term digital preservation needs of scholars and corporate researchers (Lynch, 2003; Branin, 2005). No parallel services are being developed for public library users. Given the difference in library services by type of library, public library users are likely to have less knowledge of and access to resources related to digital preservation practices.

Based on these considerations, the following dimensions of preservation and personal digital information were examined: the steps that individuals are taking towards digital

\footnotetext{
This is the accepted version of the following article: Copeland, A. J. (2011). Analysis of public library users' digital preservation practices. Journal of the American Society for Information Science and Technology, 62(7), 1288-1300, which has been published in final form at http://dx.doi.org/10.1002/asi.21553
} 
preservation; affective responses to digital information; how preservation decisions are informed; and value attributed to digital information. The personal information studied in this research is the type of information that individuals keep for their own purposes, rather than the type of information kept by institutions about an individual. Examples of personal information kept by individuals include photographs, letters, emails, music, address book, websites, diaries, family trees, videos, and personally relevant news and journal articles, and may also include financial, work, legal, and medical documents.

\section{Literature Review}

For the design of this study, three major areas ofinformation behavior research were drawn upon: everyday life information seeking (ELIS), information horizons and information source horizons, affective issues in information behavior. Additionally, personal information management research was included. Savolainen's (1995) theory of everyday life information seeking (ELIS) was used along with Savolainen's and Kari’s (2004) concept of information source horizons. Information source horizons is an extension of Sonnenwald's (1999) concept of information horizons, which was also used to frame this research. Barreau (1995) provides a conceptual framework for studying personal information management.

These theories and concepts were chosen for four reasons. Firstly, the preservation and management of personal digital information is an everyday life information activity that crosses the boundaries of work and non-work and involves cognitive and affective approaches to problem solving. Also, public libraries are designed to support the everyday life information needs of their users. Secondly, these theories and concepts can be extended to include

\footnotetext{
This is the accepted version of the following article: Copeland, A. J. (2011). Analysis of public library users' digital preservation practices. Journal of the American Society for Information Science and Technology, 62(7), 1288-1300, which has been published in final form at http://dx.doi.org/10.1002/asi.21553
} 
information behaviors beyond information seeking. Third, the use of the concept of information source horizons creates the opportunity to explore digital information objects as unique entities and to understand the cognitive distinctions made between physical and digital personal information. The personal information management framework provides the connection needed to study the information behaviors relevant to the personal information sources of public library users.

\section{Affect Issues in Information Behavior}

Important to Savolainen's theory of ELIS is the concept of Mastery of Life (MOL). MOL is the way in which one deals with problem situations and seeks information to facilitate solving problems. Savolainen presents a typology for solving problems that is either cognitive or affective and optimistic or pessimistic. In comparing cognitive and affective types, Savolainen presents a negative and common view of affective influence to problem solving. "A cognitive orientation emphasizes an analytic and systematic approach to problems whereas the affective orientation refers to the exact opposite: an emotionally laden and rather unpredictable reaction to the issues at hand” (Savolainen, 1995, p. 265).

Much of information behavior research has focused on negative aspects of emotion in information seeking, in particular the anxiety surrounding technology and the research process (Mellon, 1986; Kuhlthau, 1991; Jiao \& Onwuegbuzie, 1997; Kwon, N Onwuegbuzie,. \& Alexander, 2007); information overload (Wurman, 1989; Wurman, Sume \& Loring, 2000); information overload at work (Allen \& Wilson, 2003; Eppler \& Mengis, 2004) and in everyday life (Jacoby, Speller, \& Berning, 1974; Savolainen, 2006b).

This is the accepted version of the following article: Copeland, A. J. (2011). Analysis of public library users' digital preservation practices. Journal of the American Society for Information Science and Technology, 62(7), 1288-1300, which has been published in final form at http://dx.doi.org/10.1002/asi.21553 
While the focus has been on negative affective responses, anxiety and frustration, some studies support the notion that affective responses can positively influence the search process. James' and Nahl's (1996) research on adapting to internet use found that affective responses, like confidence, excitement, attraction, and love, played a positive role in study participants' decisions to continue to use, learn, and adapt to the internet. Additionally, recent studies support the notion that affective responses can be both positive and influential during the search processes of academic and school library users (Bowler, 2010; Gwizdka \& Lopatovska, 2009; Tenopir, Wang, Zhang, Simmons, \& Pollard, 2008).

Likewise, this research sought to understand the affective responses along with the cognitive processes that influenced participant behaviors related to the preservation of digital information. The affective responses to personal, social, and technical experiences were studied in order to understand their influence on the participants' beliefs and practices regarding digital preservation.

There is little research within the information science or information behavior fields that examines the emotional connection to one particular piece of information. There is much in the way of studies that examine cognitive evaluations and connections to specific pieces of information, particularly user studies on relevance (Barry, 1994; Tang \& Solomon, 1998; Barry \& Schamber, 1998; Choi \& Rasmussen, 2002; Xu \& Chen, 2006). Buckland's (1991) discussion of information as thing explores the idea of information as an object apart from the idea of information as knowledge or as process. Buckland states, "if you can touch it or measure it directly, it is not knowledge, but must be some physical thing, possibly information-as-thing”

\footnotetext{
This is the accepted version of the following article: Copeland, A. J. (2011). Analysis of public library users' digital preservation practices. Journal of the American Society for Information Science and Technology, 62(7), 1288-1300, which has been published in final form at http://dx.doi.org/10.1002/asi.21553
} 
(p.352). What happens to the concept of information as thing in the digital realm when information can no longer be touched or directly measured? Schamber (1996) questions the conceptualization of a document in view of electronic media. She contrasts electronic documents with physical documents and states in comparison that digital documents are easily manipulated, internally and externally linkable, readily transformable, inherently searchable, instantly transportable, and infinitely replicable. And goes on to state that "electronic documents seem to exist in the traditional sense only when individuals choose to transport or save information in some artifactual form” (p. 671).

Further, information behavior research has focused primarily on affective issues related to information seeking and use. In Information and Emotion edited by Nahl and Bilal (2007), an emergent affective paradigm in information behavior research and theory is presented. Examples of research in support of this paradigm include: information seeking and the emotions of blind individuals; the social-emotional issues related to information literacy; library and research anxiety; and affective issues in information interactions in critical care nursing. The examples from these existing studies relate to information seeking and use; whereas, this research adds to this literature by addressing the affective issues related to behaviors associated with personal information management: acquiring, evaluating and appraising, re-finding, and preserving.

\section{Information Source Horizons}

Previous studies have used the concepts of information horizons and information source horizons to study information seeking and use, whereas in this current research, information source horizons was used to explore format preference and the value of personal information.

\footnotetext{
This is the accepted version of the following article: Copeland, A. J. (2011). Analysis of public library users' digital preservation practices. Journal of the American Society for Information Science and Technology, 62(7), 1288-1300, which has been published in final form at http://dx.doi.org/10.1002/asi.21553
} 
Sonnenwald's and Wildemuth’s (2001) study used the information horizons mapping technique and a survey to collect data, participants included 11 undergraduate students (juniors and seniors ages 19 to 23) and nine corporate scientists involved in an electronic mentoring program. The survey results indicated that the students used scholarly materials from printed indices and networked resources, books from the university catalog or from browsing the shelves. Interestingly, the information horizon maps showed that the students considered many more resources than information professionals traditionally consider in studies. Many of the sources used by the students are considered non-academic or social in nature: The Learning Channel, aunts and uncles, Time magazine, career centers, and hospitals. They found that using the information horizons data gathering technique captured more information about the process and relationship between information resources than did the survey questions.

Savolainen and Kari (2004) extended Sonnenwald's (1999) concept of information horizons view that books and libraries could be considered as information horizons to include the differentiation of sources. Savolainen and Kari (2004) define information source horizons as an imaginary field which opens before the mind's eye of the information seeker. These horizons are created in the broader context of an information environment perceived of by the individual. Savolainen and Kari (2004) examined how individuals prioritized the internet as an everyday information resource when seeking information related to self-development. Eighteen (18) individuals participated in semi-structured interviews which included the information source horizons mapping technique. The technique involves graphically representing an information source horizon in term of three zones with the center zone having the greatest weight given its

\footnotetext{
This is the accepted version of the following article: Copeland, A. J. (2011). Analysis of public library users' digital preservation practices. Journal of the American Society for Information Science and Technology, 62(7), 1288-1300, which has been published in final form at http://dx.doi.org/10.1002/asi.21553
} 
closeness to the information seeker on the horizon. Points were given to each source according to zone. All sources in the first zone were given 3 points, second zone 2 points, and the third zone 1 , reflecting the value of the sources. Using this scoring system, the internet or networked sources placed third after human sources (61) points, print media (55) and networked (46). In two other studies, Savolainen $(2007 ; 2008)$ used the information source horizon data collection technique described above. In the first study, he studied the information seeking preferences of 20 environmental activists specific to information sources and channels for keeping current with daily news and events. In the second study, Savolainen analyzed the participants' information pathways in addition to their information source horizons. He used these techniques to determine criteria for source and path preference when seeking information to solve specific problems.

Huliva's (2009) research on the information seeking and use behavior of 25 Swedish and Finish archaeology professionals was informed by the theoretical framework of information horizons. At the start of each interview, participants drew a mental model of the information resources important to their daily work. The mental model was used in the manner of a checklist so that no resources were overlooked during the course of the interview. Whereas in this study, the researcher used interview questions to prime the participants' memories regarding different types of valuable personal information before asking them to fill in the zones of their information source horizons.

Through the study of how individuals value personal digital information, this current research extended the information source horizons concept and mapping technique beyond the

\footnotetext{
This is the accepted version of the following article: Copeland, A. J. (2011). Analysis of public library users' digital preservation practices. Journal of the American Society for Information Science and Technology, 62(7), 1288-1300, which has been published in final form at http://dx.doi.org/10.1002/asi.21553
} 
study of the information seeking process to information behaviors related to the acquisition, organization, preservation and value estimation of personal information.

The focus of information behavior research has been the seeking, searching, and using of information from libraries and systems that organize, maintain, and store information. Whereas in the field of human computer interaction, researchers have been more attuned to the human behaviors related to personal computing, as evidenced by the personal information management (PIM) conference has taken place via the CHI workshop venue since 2005. This research extends information behavior research through this connection to the research in personal information management.

\section{Personal Information Management}

Jones (2007) defines PIM as both the practice and the study of the "activities a person performs in order to acquire or create, store, organize, maintain, retrieve, use and distribute the information needed to complete tasks (work-related or not) and fulfill various roles and responsibilities (for example as parent, employee, friend, or community member)” (p.453). The framework used in this study is from Barreau's (1995) research on the PIM behaviors related to the use of personal computers in the workplace. Barreau framed her research in terms of four overarching behavioral areas: acquisition, organization, re-finding and/or retrieval, and maintenance. To study these behaviors in the digital environment, one must also explore of the personal digital technology that supports these behaviors.

The concepts of personal information space (PSI) and personal information collection (PIC) are key PIM concepts to this current study. A PSI includes all the information that is

This is the accepted version of the following article: Copeland, A. J. (2011). Analysis of public library users' digital preservation practices. Journal of the American Society for Information Science and Technology, 62(7), 1288-1300, which has been published in final form at http://dx.doi.org/10.1002/asi.21553 
under an individual's control: books, documents, electronic bookmarks, email messages, etc. One can only have one PSI (Jones, 2007). This concept is similar to information source horizons with the exception that information source horizons include information not under an individual's control, such as other individuals. PICs are islands in the PSI. PICs result from the conscious effort to control the information that goes into the collection and the manner in which it is organized (Jones, 2007). A PIC is a subset of an individual's information world, used when an information need occurs (Bruce, 2005). In this way, PSIs and PICs relate to the two types of information source horizons. PSI is like the stable horizon that exists across all information situations and a PIC is similar to a situation specific horizon created to address a particular information need.

Several studies have focused on the effectiveness and potential of tools to aid in organizing and re-finding of personal information. The five major areas under study are: web site management tools (Abrams, Baecker, \& Chignell, 1998; Gottlieb \& Dilevko, 2001; Dix \& Marshall, 2003; Bruce, Jones, \& Dumais, 2004); files and folders (Carroll, 1982; Barreau, 1995; Barreau \& Nardi, 1995; Jones, Phuwanartnurak, Gill \& Bruce, 2005); email (Whittaker \& Sidner, 1996; Balter, 2000; Ducheneaut \& Bellotti, 2001; Marshall, 2006; Whittaker, Bellotti, \& Gwizdka, 2006); photographs (Rodden \& Wood 2003; Cunningham \& Masoodian, 2007); and cross-tool studies (Boardman \& Sasse, 2004; Taveen, 2004; Karger \& Jones, 2006; Elsweiler, Ruthven \& Jones, 2007). The collective goal of the aforementioned research is to understand how these tools are used by individuals to manage personal information and to make recommendations for system and/or tool improvements based on those observations.

This is the accepted version of the following article: Copeland, A. J. (2011). Analysis of public library users' digital preservation practices. Journal of the American Society for Information Science and Technology, 62(7), 1288-1300, which has been published in final form at http://dx.doi.org/10.1002/asi.21553 
Studies have found that individuals’ primary cognitive strategy for refinding personal information is to browse rather than to search (Barreau, 1995; Boardman \& Sasse, 2004; Jones, Phuwanartnurak, Gill \& Bruce, 2005). The involvement of the individual in the act of organizing her information invokes the use of memory that will then later aid the recall and recognition of information over time (Lansdale, 1988). Even if a search tool recalls something, the individual may not recognize relevant information without previously established cognitive associations to it (Lansdale, 1988). Barreau (1995) found, in the digital realm, that personal and situational cues aid retrieval of items from personal collections. As Marshall (2008) points out, tools are needed to promote the "re-encountering" of personal information that is buried in one’s decade deep personal stores of information

In Whittaker's (2010) review of the literature on personal information management, he focuses his analysis on personal information curation, which he describes as keeping, managing, and exploiting of personal information. As mentioned above, he also points out that information behavior research has focused on information seeking and use rather than information curation. The focus has been on individuals searching public literature rather than their own stores of information. The concept of personal information curation is important to this research as personal digital information will need to be managed in such way as to not only be accessible but recognizable in terms of specific worth.

PIM studies have found that maintenance and organization of information is less of a priority to individuals than time-sensitive and context-driven activities such as finding and keeping (Barreau, 1995; Bruce, Jones \& Dumais, 2004). Maintenance activities include storing,

This is the accepted version of the following article: Copeland, A. J. (2011). Analysis of public library users' digital preservation practices. Journal of the American Society for Information Science and Technology, 62(7), 1288-1300, which has been published in final form at http://dx.doi.org/10.1002/asi.21553 
organizing, deleting, and reorganizing information. In the PIM literature, there is limited research on the behaviors related to digital preservation. The studies by Marshall, et al. (2006) and Marshall (2006, 2008a, 2008b) identified issued faced by technically savvy computer users when dealing with long term access to email and their own digital files.

The study of self-archiving of electronic personal records by scholars, artists, academics, and politicians has been the focus of the archival field (Kaye, et al., 2006; Kim, 2007), as is the ingestion of personal electronic records into existing institutional archives (Cunningham, 1999; Williams, et al, 2008; Davis, 2008). This research contributes to this literature by providing an understanding of public library users' approach to digital preservation of personal information. In doing so, this research fills a gap in the digital preservation research which to date has focused on the personal files and electronic manuscripts of individuals working in diplomatic, scholarly, and corporate environments.

\section{Research Questions}

1. Based on the frameworks for studying everyday life information seeking and personal information management, this study investigated the cognitive and affective strategies used by participants to preserve their own digital information given the technical environment that supports access to this information. The first two research questions address the participants' information source horizons by asking about the types of digital information stored in the participants' information spaces. The third question relates to the ELIS concept of mastery of life. This question seeks to indentify the various influences, challenges encountered and strategies employed by public library

This is the accepted version of the following article: Copeland, A. J. (2011). Analysis of public library users' digital preservation practices. Journal of the American Society for Information Science and Technology, 62(7), 1288-1300, which has been published in final form at http://dx.doi.org/10.1002/asi.21553 
users as they maintain their personal digital information and attempt to provide long term access to it. What are the characteristics of public library users’ personal digital information?

2. What motivates them to maintain personal digital information?

3. What are the technical, cognitive, affective, and social influences that contribute to the preservation of personal digital information?

The focus of this research is the individual's relationship to personal information, particularly that content which the individual desires to preserve for the mid to long term, (five years to 25 years and beyond). This time range was selected as it is difficult for individuals to anticipate specific future information needs (Bruce, 2005). Five years is long enough into the future to require digital preservation for future accessibility, (National Diet Library of Japan, 2008; PARADIGM, 2008 ) and 25 years represents a generation, implying the saving of digital items for the next generation. The timeframe encouraged participants to think about personal information beyond immediate uses and promoted thinking about the organization and maintenance of personal digital information.

\section{Methods}

\section{Participants}

As previously mentioned, public library users were specifically chosen as the focus of this study because they are underserved in terms of services and research related to digital preservation when compared to other types of library users. Further by identifying the information needs and gaps in the knowledge of public library users related to digital

This is the accepted version of the following article: Copeland, A. J. (2011). Analysis of public library users' digital preservation practices. Journal of the American Society for Information Science and Technology, 62(7), 1288-1300, which has been published in final form at http://dx.doi.org/10.1002/asi.21553 
preservation, public libraries can begin to address them and provide opportunities for their constituents to learn best practices and to provide the appropriate level of technology support for the long-term access to their information. (Copeland\& Barreau, 2011). Without first knowing what information behaviors contribute to the preservation of personal digital information, public librarians cannot begin to address the information needs of public library users in the area of digital preservation.

A large urban public library system, located on the East Coast of the United States, allowed the solicitation of participants for this research during the various Friends of the Library monthly meetings. Participants were selected based on personal computer ownership, age, and an expressed interest in the collection and long term use of personal digital information. The study included participants ages 18 to 65. Purposive sampling was employed and a mix of gender and generations are represented in the study. The Drexel Institutional Review Board (IRB) gave approval for 35 participants; however, data saturation was reached after interviewing 26 participants.

While the Friends group members were diverse in terms of race, age, and gender, the participants were mainly women, white, and educated. In sum, participants had the following characteristics: gender: 16 female, 10 male; race: 22 white, 2 black, 1 interracial Hispanic, 1 white Hispanic; education: 2 doctorates, 10 masters, 11 bachelors, 3 two years of college or less; age: 8 -20s, 4 -30s, 4 -40s, 6 -50s, and 4 -60s.

\section{Data Collection and Analysis}

This is the accepted version of the following article: Copeland, A. J. (2011). Analysis of public library users' digital preservation practices. Journal of the American Society for Information Science and Technology, 62(7), 1288-1300, which has been published in final form at http://dx.doi.org/10.1002/asi.21553 
Three different data collection methods were used: matrices, interviews, and information source horizon maps. They are presented in the order they were administered to the participants.

\section{Matrices}

Participants were asked to complete two personal information matrices. The matrices were designed to gather information on the types of digital content (photographs, word processed documents, music, etc) participants had stored in any digital devices and the various places of storage. The first matrix was designed to gather data on content types stored on various personal digital devices (laptop, cell phone, external hard drive). The second matrix is designed to gather data on content types stored on web services (YouTube, Yahoo, Snapfish).

The personal information matrices were analyzed in terms of the types and amounts of content the participants stored on digital devices and in web locations. This analysis was done in an effort to understand participants’ personal information space (PSI) and to compare the PSI of all participants. The types and amounts of digital devices and web services that contain and provide access to personal information have implications for long term information organization, preservation and an individual's ability to curate her own personal information collections for increased access. The matrices where administered first so that the researcher and participant could consider the diversity of digital formats and the distribution of content within each participant's PSI before beginning the interview.

\section{Interviews}

As influenced by the multiple case study method proposed by Zach (2006), semistructured in depth interviews were conducted with a select and small number of study

\footnotetext{
This is the accepted version of the following article: Copeland, A. J. (2011). Analysis of public library users' digital preservation practices. Journal of the American Society for Information Science and Technology, 62(7), 1288-1300, which has been published in final form at http://dx.doi.org/10.1002/asi.21553
} 
participants taken from a larger population. As is the practice with qualitative research, the interviewing guide evolved and was influenced by the dialogue with the participants (Gorman \& Clayton, 2005). The research occurred in two phases: the first four interviews led to the refinement of the data collection instruments and the addition of the matrices for the remaining 22 interviews, which took place over five months being in February 2008.

The introductory questions were designed to elicit information regarding what kinds of physical and digital information the participants collected and any values associated with either format. The next questions were included to ascertain what steps were taken by the participants to preserve and organize digital information. The next set of questions focused on cognitive and affective issues. These questions asked participants to describe both a positive and a negative experience using digital information. By asking about both types of experiences, the researcher was seeking to identify motivation for changes in information behaviors related to digital preservation. Also, participants were asked to discuss their preferences for information formats: physical or digital. With the ultimate set of questions, this research was seeking to understand what sources of information or human resources the participants turned to for technical information and how they prefer to learn technical information.

Analysis and theory building began with the first interview and evolved throughout data collection. Data analysis entailed the use of the constant comparison method (Glaser \& Strauss, 1967) to create an initial coding scheme. The constant comparative method is the most common method used for analyzing qualitative data (Agosto \& Hughes-Hassell, 2005 During this process, interviews were transcribed and then read over several times all the while noting observations in

This is the accepted version of the following article: Copeland, A. J. (2011). Analysis of public library users' digital preservation practices. Journal of the American Society for Information Science and Technology, 62(7), 1288-1300, which has been published in final form at http://dx.doi.org/10.1002/asi.21553 
the data in the form of codes. Codes are labels used to describe or represent specific instances within the data. Coding analysis permits the reduction of vast amounts data in meaningful ways (Miles \& Huberman, 1994). Codes organize the data and facilitate analysis through perceivable patterns and themes that result across coded data.

To refine the initial coding scheme that emerged, the transcripts from the interviews were divided into 15 thematic sections. This allowed for easier comparison across participants as well as a more focused approach to analyzing each question. Codes were reviewed and revised for each question starting with the first response and then added to or modified in response to analyzing each subsequent participant response to that question. This process was repeated, modifying the coding scheme throughout the analysis of all interview questions. Table 4 provides an example of the coding scheme for the question regarding a negative experience with technology. NVivo 7.0, a software program designed to aid the qualitative researcher, was used during the analysis to organize the coded text.

The coding scheme was evaluated using a measure of inter-coder reliability. The entire transcript corpus was coded first by the researcher and then a smaller subset of interview responses, approximately ten percent of the data, from five participants diverse in age and gender were selected and coded by two other coders for coding consistency checks. The two coders were $\mathrm{PhD}$ candidates in information studies trained in qualitative research methods and specifically in grounded theory. The inter-coder reliability measurement of agreement was $81 \%$ and 89\% which are both greater than the established benchmark of 80\% (Holsti, 1969).

Information Source Horizons Maps

This is the accepted version of the following article: Copeland, A. J. (2011). Analysis of public library users' digital preservation practices. Journal of the American Society for Information Science and Technology, 62(7), 1288-1300, which has been published in final form at http://dx.doi.org/10.1002/asi.21553 
After the participants completed the interview, they were given two blank maps to fill in the three zones of their information source horizons. In the first map, participants were asked to consider personal physical and digital information that is of value to them across all situations in everyday life. In the center zone, participants were to indicate the information of most value to them in their daily life. In the middle zone, they indicated the next most valuable, and in the outermost zone the next most. In other words, the information decreased in value as they moved towards the outer zone.

In the second map, participants were asked to consider personal information they would like to preserve for at least five years, but as long as 25 years and beyond. With the most valued information items clearly identified, participants were then asked to detail the criteria they used for determining that value and how those were items stored and maintained.

The information source horizons maps were analyzed in terms of what types of information items the participants valued and why. The zones illustrate and contrast the types of items valued most for everyday use and long term preservation. The value attributed to each item was measured using Savolainen \& Kari’s (2004) system of weighting each item in accordance with its location on the maps. Values attributed to items in the center zone received 3 points, the next most outer zone 2 points, and then next most 1 . The items closest to the participant on their horizon are given the greatest weight because the position indicates greater value.

Again using the constant comparative method, values were coded and seven themes emerged from the codes. Points attributed to each item were then assigned to one of the seven over-arching themes as illustrated in Figure 1. Through the use of the information source horizon

This is the accepted version of the following article: Copeland, A. J. (2011). Analysis of public library users' digital preservation practices. Journal of the American Society for Information Science and Technology, 62(7), 1288-1300, which has been published in final form at http://dx.doi.org/10.1002/asi.21553 
technique, the participants provided another perspective on digital items of value other than that provided during the interview. In combination, the two data gathering techniques provide a triangulated approach to understanding value as it relates to personal digital information.

Additionally, each item was identified as physical, digital, or existing in both formats. Two other formats were indicated by participants: verbal and mental. Verbal refers to spoken conservation with other human beings and mental refers to information which is stored in an individual's memory. Each item's format or formats was assigned points given the location of the item on the maps.

\section{Limitations}

One limitation of this study is that findings are not fully generalizable to the larger population of U.S. public library users. The goal of qualitative research, however, is not generalizability, but transferability (Lincoln \& Guba, 1985, p. 297). Qualitative research seeks to create a very detailed description of characteristics of a smaller pool of participants than quantitative research typically employs. Transferability indicates that the findings can do much to describe the behaviors of a similar pool of people, but it is understood that there are always variances in human behavior. As previously mentioned, the study participants volunteered to participate which can introduce bias and were mostly white, educated females, which limits the overall representativeness of the study and the transferability of the findings. Thus, the results of this study are intended to be largely transferable to the broader population of public library users, ages 18 to 65, but some variance is expected due to context.

\footnotetext{
This is the accepted version of the following article: Copeland, A. J. (2011). Analysis of public library users' digital preservation practices. Journal of the American Society for Information Science and Technology, 62(7), 1288-1300, which has been published in final form at http://dx.doi.org/10.1002/asi.21553
} 
This research examined information behaviors of the individual in the context of everyday life and has chosen public library because public libraries provide resources and services in support of everyday life and for other reasons previously mentioned. Given this, public library users are likely to be more aware of information resources and services in general than are non-public library users. This is a limitation of the study in that this awareness is likely but not certain to make public library users more cognizant of issues related to information organization and management as it relates to everyday information uses than are non-public library users.

Lastly, the extent to which an individual participant's personal information environment can be quantified and comprehensively described is limited by the inability to examine all their personal digital content stored across all personal devices and networked services. The estimates of amounts and descriptions of content and storage locations provided by participants are intended to serve as guide to understanding participants' environments rather than a definitive measure.

\section{Findings}

Qualitative research studies use multiple methods of data collection to provide multiple perspectives to strengthen and validate the themes that emerge from the data as a whole.

Therefore, the findings will be presented in terms of the four major themes to emerge rather than categorically in response to each data collection method.

Technical Issues

This is the accepted version of the following article: Copeland, A. J. (2011). Analysis of public library users' digital preservation practices. Journal of the American Society for Information Science and Technology, 62(7), 1288-1300, which has been published in final form at http://dx.doi.org/10.1002/asi.21553 
As indicated by the matrices, most digital content kept by participants was born digitally. Only a few participants had digitized content: scanned documents $(\mathrm{N}=4)$, scanned photographs $(\mathrm{N}=2)$ and scanned objects $(\mathrm{N}=1)$. Participants relied on a variety of digital devices and Microsoft products to create content. Of the 18 content types identified by participants as being collected, the following, Table 1, represents the content types collect by more than half the participants.

TABLE 1. Content types stored by the participants, $\mathrm{N}=22$.

\begin{tabular}{ll}
\hline Digital Content Type & Number of Participants \\
\hline Photographs & 26 \\
Word Documents & 26 \\
Music & 26 \\
Email & 26 \\
Excel Spreadsheets & 20 \\
Video & 19 \\
PowerPoint & 19 \\
\hline
\end{tabular}

These results indicate that personal devices and client-side software were used to create, store, and maintain content. All participants but one $(\mathrm{N}=25)$ used their desktop or laptop to as their first and primary means of storage for their digital content.

Kept digital content must ultimately be stored on a device or web location. All 22 participants completing the matrices stored more content types (range 6 to 18) on more types of personal digital devices (range 3 to 10) than they did on web locations (respectively: range 0 to 11 types; range 0 to 5 locations). Digital devices were used to store content four to one when compared to web storage locations. All study participants $(\mathrm{N}=26)$ stored digital content in a distributed manner without a unifying repository or organizational structure for their content.

This is the accepted version of the following article: Copeland, A. J. (2011). Analysis of public library users' digital preservation practices. Journal of the American Society for Information Science and Technology, 62(7), 1288-1300, which has been published in final form at http://dx.doi.org/10.1002/asi.21553 
Savolainen's and Kari’s (2004) weighted point system was used to understand the extent to which digital formats were valued for the participants’ everyday and the long term information needs. Table 2 indicates that digital formats (315 points) are valued nearly twice as much as physical formats (168) in the context of everyday information needs. The increasing importance of digital information to everyday life is supported by this finding. While physical formats (231 points) are more prominent than digital formats (217.5) in the context of information valued for long term use - they are just barely so.

TABLE 2. Formats of personal content from everyday and long term information source horizons maps, $\mathrm{N}=25$.

\begin{tabular}{l|l|l|l|l}
\hline & Digital & Physical & Mental & Verbal \\
\hline Everyday & 315 & 168 & 14 & 8 \\
Long Term & 217.5 & 231 & 2 & 1 \\
\hline
\end{tabular}

\section{Cognitive Strategies}

When asked why they stored their digital content, two overall categories emerged: personal and functional. As indicated by Table 3, personal reasons indicate both cognitive and affective motivations for saving content and functional reasons speak to the convenience of digital information.

TABLE 3: Reasons for saving digital information, $\mathrm{N}=26$.

\begin{tabular}{|c|c|}
\hline $\begin{array}{l}\text { Reasons for Saving Digital } \\
\text { Information }\end{array}$ & $\begin{array}{l}\text { Number of } \\
\text { Participants }\end{array}$ \\
\hline \multicolumn{2}{|l|}{ Personal } \\
\hline Future Reference & 15 \\
\hline Connection to Self & 8 \\
\hline Emotional Attachment & 5 \\
\hline Sharing & 4 \\
\hline Evidence & 4 \\
\hline Represent Memories & 3 \\
\hline Investment of time & 3 \\
\hline
\end{tabular}

This is the accepted version of the following article: Copeland, A. J. (2011). Analysis of public library users' digital preservation practices. Journal of the American Society for Information Science and Technology, 62(7), 1288-1300, which has been published in final form at http://dx.doi.org/10.1002/asi.21553 


\begin{tabular}{ll} 
Connection to Family & 2 \\
Private & 1 \\
Paid for it & 1 \\
Functional & \\
Increased Access & 5 \\
Born Digital & 4 \\
Saves Everything & 3 \\
Facilitates Editing & 2 \\
Work In Progress & 2 \\
Use Everyday & 2 \\
Easy to Organize & 2 \\
\hline
\end{tabular}

Most of the participants saved digital files in anticipation of a yet to be determined information need $(\mathrm{N}=15)$. However, as all participants $(\mathrm{N}=26)$ created file names inspired by the current context rather than long term access there appears a mismatch between the reason for saving the content and file naming practices.

The following comments from Lisa and Victoria, illustrate this point:

(Lisa) I name it according to its content.

(I) Can you give me an example?

(Lisa) Like, “kids at the beach”. And then I will put the year.

(I) And do you then put it in a folder?

(Lisa) Yeah. Well, I don’t know if it’s in a folder right now. I think it’s just

This is the accepted version of the following article: Copeland, A. J. (2011). Analysis of public library users' digital preservation practices. Journal of the American Society for Information Science and Technology, 62(7), 1288-1300, which has been published in final form at http://dx.doi.org/10.1002/asi.21553 
in My Pictures. Like, within My Documents there’s My Pictures.

(Victoria) If it's a file that I've been working on, on my desktop, which is where I do most of my word processing and other things, I first save it to my hard drive.

(I) When you name the file - how do you name it?

(Victoria) If I type up a letter for my father it would be "letter to" whoever it is, possibly a date and then it's saved in the folder under "Dad", for instance.

Browsing to re-find personal content was the norm $(\mathrm{N}=21)$, likely owing to the limitations imposed by digital devices on metadata creation and search functionality. Participants relied on informal organization for browsing. Organization of file folders relied heavily on broadly classified folders to order and define content topicality. Like file names, folder classification was also inspired by the current context of the information use. Photographs were often only identified at the folder level, thereby making this content less accessible without text to search. The comments from Eleanor and Wendy illustrate this point and that their own memories hinder the recall process over time.

(Eleanor) My file structure is pretty good, I browse, the Apple has the little search thing called Spotlight which isn't bad, and if I cannot remember where it might have gone, I will do a full text search for it, but I browse first.

(Wendy) I usually search the documents; I try to be careful about labeling folders.

(I) Do you search first?

(Wendy) When it's not obvious where it's located, or if it's old, or I can't remember which folder I put it in.

(I) Would you say you browse your folders more or you search more?

(Wendy) I probably browse more first and search as a last result.

This is the accepted version of the following article: Copeland, A. J. (2011). Analysis of public library users' digital preservation practices. Journal of the American Society for Information Science and Technology, 62(7), 1288-1300, which has been published in final form at http://dx.doi.org/10.1002/asi.21553 
Participant knowledge of preservation practices related to storage media and file format selection were limited. All participants $(\mathrm{N}=26)$ allowed digital devices and or/Microsoft Office software to determine which formats they used rather than personal preference or knowledge of which formats were best for long term access, most of the time. Most participants $(\mathrm{N}=17)$ indicated they had no knowledge of digital format differences and only two $(\mathrm{N}=2)$ indicated they were knowledgeable of the formats they used and knew which formats were best for long term access.

In general, participants lacked specific knowledge regarding which storage devices/locations or file formats were considered best for providing long term access to digital content. Half of the participants selected redundant storage space based on ease of use $(\mathrm{N}=11)$. While participants were mainly motivated to save information for future reference $(\mathrm{N}=15)$, when selecting redundant storage reliability of the storage device was not considered by any of the participants. Knowledge regarding information maintenance or preservation was mostly obtained from interactions with other people, such as family and friends $(\mathrm{N}=8)$, retail employees $(\mathrm{N}=5)$, community of practice $(\mathrm{N}=5)$, and co-workers $(\mathrm{N}=4)$. The only other form of information source consulted was the internet $(\mathrm{N}=8)$.

Making duplicate copies of personal content emerged as the only preservation strategy employed. Most participants $(\mathrm{N}=10)$, copied their content to at least two devices/locations other than the original location, six participants copied content to one other device/location, five participants to three other devices/locations, one participant to four other locations, and only one

This is the accepted version of the following article: Copeland, A. J. (2011). Analysis of public library users' digital preservation practices. Journal of the American Society for Information Science and Technology, 62(7), 1288-1300, which has been published in final form at http://dx.doi.org/10.1002/asi.21553 
individual did not intentionally make redundant copies of any of his content. Overall most content was copied from a lap top or desk top to an external hard drive, seven and five participants respectively.

Participants began creating duplicate copies of their content a result of individuals losing content due to technology malfunctioning $(\mathrm{N}=12)$ or inoperability issues related to technology upgrades $(\mathrm{N}=6)$. Digital devices are viewed as generally stable but also as bound to fail or disappoint eventually. Frank illustrates this phenomenon:

(Frank) All my digital files I back up weekly to an external hard drive. Also when I'm working on them I back them up to, well let's see I have a process for this, I back up to a flash drive regularly at the end of the day I back it up to an offsite tool, the server that hosts my web site and at the end of the week I back up everything to a hard drive. And that is a lesson hard learned because of a fatal hard drive crash on my lap top about 3 years that ate up some irreplaceable writing that I had down, stories, some fiction that I was working on that were getting ready for publication. One of those lessons you don't have to learn twice.

Frank went on to describe the negative emotions he felt after losing the entire contents of his hard drive. While negative affective responses to technology motivated the primary preservation strategy employed, positive affect also encouraged the development of preservation practices.

\section{Affective Strategies}

As mentioned above, most of the participants' negative experiences involved problems with digital devices and loss of content, either a technology malfunction or a system incompatibility that resulted from upgrading operating systems. User error accounts for the second most frequent negative experience $(\mathrm{N}=7)$. Frustration $(\mathrm{N}=9)$ was the emotion most associated with these experiences, followed by anger $(\mathrm{N}=7)$. Table 4 describes the various

This is the accepted version of the following article: Copeland, A. J. (2011). Analysis of public library users' digital preservation practices. Journal of the American Society for Information Science and Technology, 62(7), 1288-1300, which has been published in final form at http://dx.doi.org/10.1002/asi.21553 
negative experiences and provides an example of how data collected from the interviews were coded and emergent themes identified.

TABLE 4. Negative experiences with digital information and related emergent codes and themes, $\mathrm{N}=26$.

\begin{tabular}{|c|c|c|}
\hline Data from Interviews & Codes & Themes \\
\hline Deleted stuff by accident & User Error & Cognitive Influence \\
\hline Did not save as thought & User Error & \\
\hline $\begin{array}{l}\text { Could not find content saved to hard } \\
\text { drive }\end{array}$ & User Error & \\
\hline $\begin{array}{l}\text { Files from work not supported by } \\
\text { home software }\end{array}$ & User Error & \\
\hline Reformatted computer accidentally & User Error & \\
\hline Computer destroyed physically & User Error & \\
\hline Computer crashed - lost all content & Device failure & Technological Influence \\
\hline Wireless system goes down & $\begin{array}{l}\text { Limitation of } \\
\text { technology }\end{array}$ & \\
\hline $\begin{array}{l}\text { PDA stripped going through metal } \\
\text { detector }\end{array}$ & Device failure & \\
\hline $\begin{array}{l}\text { Not knowing if email reaches its } \\
\text { destination }\end{array}$ & $\begin{array}{l}\text { Limitation of } \\
\text { technology }\end{array}$ & \\
\hline External hard drive crashed & Device failure & \\
\hline $\begin{array}{l}\text { Technology upgrade to existing } \\
\text { software created problems }\end{array}$ & Incompatibility issues & \\
\hline $\begin{array}{l}\text { Lost content due to operating system } \\
\text { incompatibility }\end{array}$ & Incompatibility issues & \\
\hline Virus destroyed disk and PC & $\begin{array}{l}\text { Social Connection \& } \\
\text { Device Failure }\end{array}$ & $\begin{array}{l}\text { Social \& Technological } \\
\text { influence }\end{array}$ \\
\hline Upsetting e-mails from ex-husband & Emotional Connection & Social Influence \\
\hline
\end{tabular}

This is the accepted version of the following article: Copeland, A. J. (2011). Analysis of public library users' digital preservation practices. Journal of the American Society for Information Science and Technology, 62(7), 1288-1300, which has been published in final form at http://dx.doi.org/10.1002/asi.21553 
Again, Savolainen's and Kari’s (2004) weighted point system was used to calculate and compare the values associated with personal information. Figure 1 illustrates the comparison. In the everyday context, the personal information is most valued for communication with other people. In the long term context, the personal information is most valued for the connection to emotions associated with friends and family motivated by the documentation of life events.

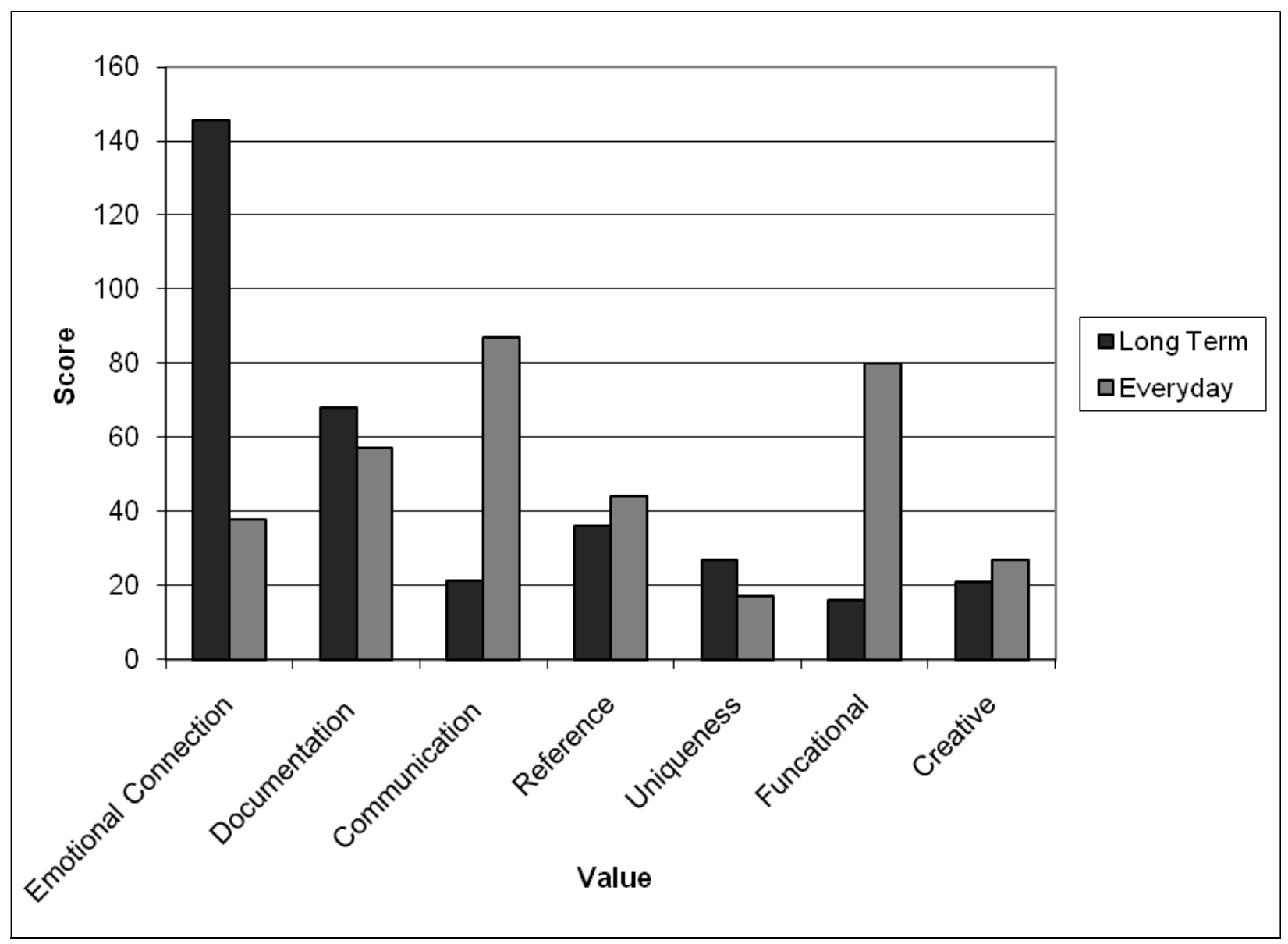

FIG 1. Comparison of values associated with personal information for everyday and long term information uses.

This is the accepted version of the following article: Copeland, A. J. (2011). Analysis of public library users' digital preservation practices. Journal of the American Society for Information Science and Technology, 62(7), 1288-1300, which has been published in final form at http://dx.doi.org/10.1002/asi.21553 
In discussing positive affective experiences with digital information, participants described experiences that were valuable to them because of the ability to share, give or exchange digital files with others $(\mathrm{N}=11)$ and because of their ability to be creative with technology and the pride they take in their digital creations $(\mathrm{N}=9)$. Six of the 11 positive experiences related to sharing involved photographs through email and/or social networking sites.

\section{Social Strategies}

As mentioned previously, connections with other people figured most prominently in explaining why personal information was of value in the context of both everyday and long term use. Connections with others may help individuals determine which of their digital information is most valuable to them and help provide long term access to important representations of personal memories. For example, participants were unintentionally duplicating their personal digital content as a result of social interactions through email and social networking sites. While this further distributes personal content, information shared is likely to be personal information that is more valuable than information which is not shared. Also, shared personal information may be easier to find again over long periods of time given the social conversation, context and networks associated with the information. With her comments, Paula illustrates this point.

(Paula) I think my prom pictures, I remember all my friends had all their own separate digital cameras, we all sent all these pictures to everyone through email and I got to go through all the goofy ones and save them and delete the ones I didn't want.

(I) Some of these are your own and some are your friends?

$$
\text { (Paula) Yes }
$$

\footnotetext{
This is the accepted version of the following article: Copeland, A. J. (2011). Analysis of public library users' digital preservation practices. Journal of the American Society for Information Science and Technology, 62(7), 1288-1300, which has been published in final form at http://dx.doi.org/10.1002/asi.21553
} 
(I) You received them through email?

(Paula) Yes and we also used MySpace for some things

(I) Does your prom has a MySpace page?

(Paula) No we just put on them in our photos on MySpace, you'd just right click and save them.

(I) Why did you decide to save these?

(Paula) They are of my prom, it’s just one of those things, it was just a very fun time. And the pictures are nice.

Robert discusses how he was able to restore some of his work files after a fatal hard drive crash by accessing the content he unintentionally duplicated as a result of sharing content with coworkers.

(Robert, Age 37) So, it was a little bit of extra work, but what I did was I went to my email and a lot of the documents that were the most important I had emailed to other people, so it was in my sent items folder. And then I would ask other people, say hey (people on my team that I work with) hey, email me, you know, the following document. So, I was able to reconstitute some of the more important stuff.

These two examples illustrate how email and social networking sites serve as storage by default. Social connections to others presents a strategy for identifying content likely to be valuable over the long term.

\section{Discussion}

Technological affordances facilitate the creation, storage, and accession of digital information. However given the current design of personal digital devices, affordances have the potential to become constraints. Identifying and re-finding personal digital information of value becomes more difficult as the volume of digital information increases. With the passage of time,

This is the accepted version of the following article: Copeland, A. J. (2011). Analysis of public library users' digital preservation practices. Journal of the American Society for Information Science and Technology, 62(7), 1288-1300, which has been published in final form at http://dx.doi.org/10.1002/asi.21553 
an individual's cognitive associations to specific activities or events fade. Documentation of new experiences begins to outpace older documentation. Further, newer technologies that support information access and creation continually replace older ones and as a result personal knowledge of and access to older technologies becomes less used and less available. The model in figure two represents this process, a process which emerged from the data collected.

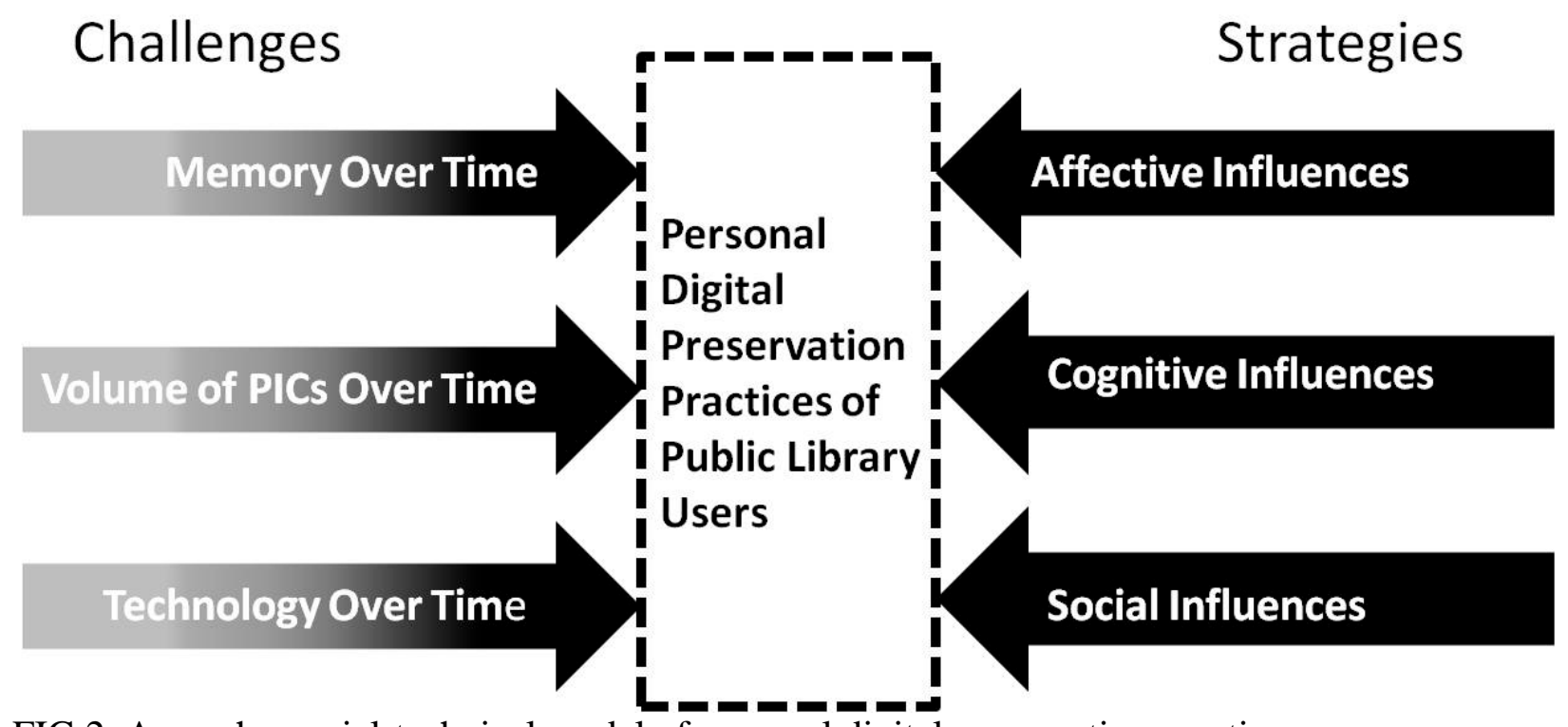

FIG 2. A psycho-social-technical model of personal digital preservation practices.

This model illustrates the technical, cognitive, affective, and social influences likely to affect the preservation practices of public library users. These influences informed the participants’ decisions to create, acquire, organize, and share personal information. Cognitive, affective, and social influences can also be viewed as strategies beneficial to the preservation of personal digital information and for dealing with the challenges presented by technology and memory present over time.

This is the accepted version of the following article: Copeland, A. J. (2011). Analysis of public library users' digital preservation practices. Journal of the American Society for Information Science and Technology, 62(7), 1288-1300, which has been published in final form at http://dx.doi.org/10.1002/asi.21553 
In agreement with existing research, this study found that the participants’ informal organizational practices and use of limited metadata applied in form of file and folder names inspired by the current context offer limited support for cueing human memory to recall and refind specific content(Barreau,1995; Bruce, Jones \& Dumais, 2004; Boardman \& Sasse, 2004; Karger. \& Jones, 2006). This study contributes to this established understanding the idea that social connections have the potential to cue human memory for re-finding personal information of value.

Participants shared information with others because of the emotional connection the information represented. Also, participants wanted most to preserve digital information that evoked emotional connections to personal accomplishments and to family and friends.

Therefore, information shared is likely to be more valuable than information which is not shared because of this connection. Shared personal information is duplicated in the process. Further, the sharing process becomes a social strategy for providing access to valuable information over long periods of time given the social conversation, context and networks associated with the information. Further, the study findings support the ELIS framework for mastery of life (Savolainen, 1995) regarding participants using both cognitive and affective strategies used to find digital preservation solutions. Counter to the current understanding of framework, the findings support that positive and not just negative affective responses were employed in the process of gaining a greater understanding of the problem. Additionally, this research suggests

This is the accepted version of the following article: Copeland, A. J. (2011). Analysis of public library users' digital preservation practices. Journal of the American Society for Information Science and Technology, 62(7), 1288-1300, which has been published in final form at http://dx.doi.org/10.1002/asi.21553 
that social influences be considered part from that of social class in the ELIS framework and that social strategies be considered along with cognitive and affective strategies.

While the duplication and distribution of digital files from a personal computer or lap top to other digital devices and/or web locations emerged as the primary preservation strategy, there is much potential in exploiting the other main finding that have emerged from this study. Knowing that information shared is information valued has implications for teaching individuals how to organize, re-find and select content which they wish to preserve. Also, researchers interested in designing tools to help individuals manage their personal information might consider the ways in which social strategies are likely to enhance access to and organization of personal information over many years. Whether through the design of teaching methods or tools, individuals can begin to create PICs within their PSI through the process of information appraisal and selection.

Lastly, the findings have implications for the study and practice of archives as individuals and archivists will need to understand how best to manage the challenges presented to digital preservation by technology and time. As archivists are increasingly dealing with digital manuscript collections, the findings have important implications for appraisal and post-custodial archival strategies. They are also useful for identifying critical decision points when digital curation issues are best addressed and may involve the collaboration of archivist and individual creators of digital information collections.

\section{Future Research}

This is the accepted version of the following article: Copeland, A. J. (2011). Analysis of public library users' digital preservation practices. Journal of the American Society for Information Science and Technology, 62(7), 1288-1300, which has been published in final form at http://dx.doi.org/10.1002/asi.21553 
Not one participant mentioned losing content due to a web site and/or storage malfunction yet most every participant had a digital loss due to devices malfunctioning. Research is needed to explore if in fact web based storage is more reliable and if it is, what would encourage individuals to store content on the web over digital devices? Further research could explore how much personal content is stored on the web and what impact this has on one's personal information space (PSI). Placing information on the web lessens the control one has over her PSI as the desire for privacy and control is in direct conflict with relying on corporate web space for personal information access and use.

A long term study of personal information management is needed to understand how the combination of access issues affect an individual's ability to access his own content. These issues would include media durability, system and software changes, and organizational structures that provide access to the content of personal files. Considering the participants’ limited knowledge of preservation practices, research is needed on how best to teach individuals to preserve their own digital information. In support of this, future research is needed to understand how public libraries can help contribute to this learning process.

\section{Conclusion}

This study is situated in the context of the current transition in communication from the prominence of analog formats to digital. It is a time when the personal experiences of and relationships to information possessions and to representations of memories is changing from the tangible to the intangible, from those that are fixed in time and space to those that are mutable and fluid across space. Digital photos and digital music files represent two major cultural and

\footnotetext{
This is the accepted version of the following article: Copeland, A. J. (2011). Analysis of public library users' digital preservation practices. Journal of the American Society for Information Science and Technology, 62(7), 1288-1300, which has been published in final form at http://dx.doi.org/10.1002/asi.21553
} 
technical shifts in the format of everyday information possessions. Until recently, individual consumers and libraries alike (with some exceptions) have focused on the benefits of access and ease of content creation in the digital environment and have not fully considered the need to preserve digital content over the long term. These findings related to public library users fills a gap in the digital preservation research which to date has focused on diplomatic, scholarly, and corporate information.

Considering the study findings, public librarians could become a vital resource for those individuals seeking help to maintain their personal information for long term access. Collection creation, maintenance, and preservation (physical or digital), are knowledge intensive processes. Public libraries could provide community members with trusted sources of information related to digital information management and preservation. Libraries and archives have a tradition of helping individuals care for personal tangible information such as letters and photographs. This tradition needs to extend to personal digital information.

Generally, public libraries have connected with users by providing access to computers and networked proprietary resources for personal use, but have not succeeded nearly as well at connecting with individuals in their personal computing spaces. Public libraries can begin to explore the role of community members in public library digital collections and on the connections between the expertise of information professionals and the knowledge needed to curate and manage personal information collections.. In this way, librarians and LIS researchers can become a driving force behind helping the public to preserve and organize their personal information collections.

This is the accepted version of the following article: Copeland, A. J. (2011). Analysis of public library users' digital preservation practices. Journal of the American Society for Information Science and Technology, 62(7), 1288-1300, which has been published in final form at http://dx.doi.org/10.1002/asi.21553 


\section{Acknowledgements}

This research was supported by the Laura Bush 21st Century Librarian Fellowship provide by the Institute of Museum and Library Services. The author wishes to thank the reviewers, Hsinliang Chen and Robin Moeller for their advice and feedback on this manuscript.

\section{References}

Abrams, D., Baecker, R.M., and Chignell, M. (1998). Information archiving with bookmarks: Personal web space construction and organization. Human Factors in Computing Systems: Proceedings of the CHI '98 Conference, (p. 41-48), New York: ACM.

Agosto, D. E. \& Hughes-Hassell, S. (2005). People, places, and questions: An investigation of the everyday life information-seeking behaviors of urban young adults. LISR, 27, 141163.

Allen, D. \& Wilson, T. (2003). Information overload: Context and causes. The New Review of Information Research: Studies of information seeking in context. Proceedings of ISIC, 2002, 4, 31-44.

Barreau, D. (1995). Context as factor in personal information management systems. JASIS, 46(5), 327-339.

Barreau, D. \& Nardi, B. (1995). Finding and reminding: file organization from the desktop. ACM SIGCHI Bulletin, 27(3), 39-43.

Barry, C. (1994) User-defined relevance criteria: An exploratory study. JASIS 45, 149-159.

This is the accepted version of the following article: Copeland, A. J. (2011). Analysis of public library users' digital preservation practices. Journal of the American Society for Information Science and Technology, 62(7), 1288-1300, which has been published in final form at http://dx.doi.org/10.1002/asi.21553 
Barry, C. \& Schamber, L. (1998). Users' criteria for relevance evaluation: A crosssituational comparison. Information Processing \& Management, 34(2-3), 219-236.

Beagrie, N. (2005, June). Plenty of room at the bottom? Personal digital libraries and Collections. D-Lib Magazine 11(6). Retrieved from http://www.dlib.org/dlib/june05/beagrie/06beagrie.html.

Boardman, R. \& Sasse, M. A. (2004). “Stuff goes into the computer and doesn’t come Out” a cross-tool study of personal information management. CHI 2004. April 24-29, 2004. Vienna, Austria.

Bowler, L. (2010). The self-regulation of curiosity and interest during the information search process of adolescent students. JASIS\&T, 61(7), 1332-1344.

Bradley, K. (2007). Defining digital sustainability. Library Trends, 56(1), 148-163.

Branin, J. (2005). Institutional repositories. In Encyclopedia of Library and Information Science. Ed. Miriam Drake. Pp. 237-248.

Bruce, H. (2005, April). Personal, anticipated information need. Information Research, 10(3). Retrieved from http://informationr.net/ir/10-3/paper232.

Bruce, H., Jones, W., \& Dumais, S. (October, 2004). Information behavior that keeps found things found. Information Research, 10(1). Retrieved from http://informationr.net/ir/10-1/paper207.html.

Buckland, M. (1991). Information as thing. JASIS, 42(5), 351-360.

Carroll, J. (1982). Creating names for personal files in an interactive computing environment. Journal of Man-Machine Studies, 16, 405-438.

This is the accepted version of the following article: Copeland, A. J. (2011). Analysis of public library users' digital preservation practices. Journal of the American Society for Information Science and Technology, 62(7), 1288-1300, which has been published in final form at http://dx.doi.org/10.1002/asi.21553 
Chen, S. (2001, March). The paradox of digital preservation. Computer, 24-28.

Choi, Y. \& Rasmussen, E. (2002). Users' relevance criteria in image retrieval in American history. Information Processing \& Management, 38(5), 695-726.

Copeland, A. \& Barreau, D. (2011). Helping people to manage and share their digital information: A role for public libraries. Library Trends. [In Press].

Cunningham, A. (1999). Waiting for the ghost train: Strategies for managing electronic personal records before it is too late. Archival Issues: Journal of the Midwest Archives Conference, 24 (1), 55-64.

Cunningham, S. J. \& Masoodian, M. (2007). Identifying personal photo digital library features. Proceedings of the 7th ACM/IEEE-CS Joint Conference on Digital Libraries (pp. 400401). New York, NY: Association for Computing Machinery

Davis, S. E. (2008, Spring/Summer). Electronic planning in “collecting” repositories. The American Archivist, 71, 167-189.

Dix, A. \& Marshall, J. (2003). At the right time: when to sort web history and bookmarks. In Proceedings of Human Computer Interaction International 2003.

Ducheneaut, N. \& Bellotti, V. (2001). E-mail as habit: an exploration of embedded Personal information management. Interactions, 8(5), 30-38.

Elsweiler, D., Ruthven, I., \& Jones, C. (2007). Towards memory supporting personal information management tools. JASIS\&T, 58(7), 924-946.

Eppler, M. \& Mengis, J. (2004). The concept of information overload: A review of

This is the accepted version of the following article: Copeland, A. J. (2011). Analysis of public library users' digital preservation practices. Journal of the American Society for Information Science and Technology, 62(7), 1288-1300, which has been published in final form at http://dx.doi.org/10.1002/asi.21553 
literature from organization science, accounting, marketing, MIS, and related disciplines. The Information Society, 30, 325-344.

Holsti, O. R. (1969). Content Analysis for the Social Sciences and the Humanities.

Reading, MA: Addison-Wesley.

Glaser, B. B \& Strauss, A. (1967). The Constant Comparative Method of Qualitative Analysis. In The discovery of grounded theory: Strategies for qualitative Research (pp. 101-115). Piscataway, NJ: Aldine Transaction.

Gottlieb, L. \& Dilevko, J. (2001). User preferences in the classification of electronic Bookmarks: Implications for a shared system. JASIS\&T, 52(7), 517-535.

Gorman, G. \& Clayton, P. (2005). Qualitative Research for the Information Professional. $2^{\text {nd }}$ Edition. London: Facet Publishing.

Gwizdka, J. \& Lopatovska, I. (2009). The role of subjective factors in the information search process. JASIS\&T, 60(12), 2452 -2464.

Hedstrom, M. (1997). Digital preservation: A time bomb for digital libraries. Computers and the Humanities, (33)3, 189-202.

Huvila, I. (2009). Analytical information horizon maps. Library \& Information Science Research, 31(1), 18-28.

Jacoby, J., Speller, D., \& Berning, C. (1974). Brand choice behavior as a function of information load: Replication and extension. Journal of Consumer Research, $1,33-42$.

This is the accepted version of the following article: Copeland, A. J. (2011). Analysis of public library users' digital preservation practices. Journal of the American Society for Information Science and Technology, 62(7), 1288-1300, which has been published in final form at http://dx.doi.org/10.1002/asi.21553 
James, L. and Nahl, D. (1996). Achieving focus, engagement, and acceptance: Three phrases of adapting to Internet use. EJVC: Electronic Journal of Virtual Culture, (4)1. Retrieved from http://www2.hawaii.edu/ nahl/articles/ejvc.html.

Jiao, Q. \& Onwuegbuzie, A. (1997). Antecedents of library anxiety. Library Quarterly,67, 372389.

Jones, W. (2007). Personal information management. ARIST, 41, 453-504.

Jones, W., Phuwanartnurak, A., Gill, R., \& Bruce, H. (2005). Don't take my folders away!: Organizing personal information to get things done. Conference on Human Factors in Computing Systems (pp. 1505-1508). New York, NY: Association for Computing Machinery.

Karger, D. \& Jones, W. (2006, January). Data unification in personal information management. Communications of the ACM, 49(1), 77-82.

Kaye, J. J., et al. (2006) To have and to hold: Exploring the personal archive. CHI 2006 (pp. 274285), April 22-27, 2006, Montréal, Québec, Canada.

Kim, J. (2008). Motivating and impeding factors affecting faculty contribution to institutional repositories. Journal of Digital Information, 8(2). Retrieved from http://journals.tdl.org/jodi/article/viewArticle/193/177.

Kwon, N, Onwuegbuzie, A. \& Alexander, L. (2007). Critical thinking disposition and library anxiety: Affective domains on the space of information seeking and use in academic libraries. College \& Research Libraries, 68(3), 268-278.

This is the accepted version of the following article: Copeland, A. J. (2011). Analysis of public library users' digital preservation practices. Journal of the American Society for Information Science and Technology, 62(7), 1288-1300, which has been published in final form at http://dx.doi.org/10.1002/asi.21553 
Kuhlthau, C. (1991) Inside the search process: Information seeking from the user's perspective. JASIS, 42 (5), 361-371.

Kuny, T. (1998). The Digital Dark Ages? Challenges in the preservation of electronic information. International Preservation News, No. 17. Retrieved from http://www.ifla.org/VI/4/news/17-98.htm\#2.

Lansdale, M. (1988). The psychology of personal information management. Applied Ergonomics, 19(1), 55-66.

LeFurgy, W. (2005, Summer). Building preservation partnerships: The Library Congress National Digital Information Infrastructure and Preservation Program. Library Trends, 54 (1), 163-72.

Lincoln, Y \& Guba, E. (1985). Naturalistic Inquiry. Thousand Oaks, CA: Sage Publications, Inc.

Lyman, P. \& Varian, H. (2003). How much information 2003? Retrieved from http://www2.sims.berkeley.edu/research/projects/how-much-info-2003/ on January 3, 2008.

Lynch, C. (2003). Institutional repositories: Essential infrastructure for scholarship in the digital age. portal: Libraries and the Academy, 3(2), 327-336.

Marshall, C. (2006). Maintaining personal information: Issues associated with long-term storage, preservation, and access. Retrieved on August 14, 2006 from http://www.csdl.tamu.edu/ marshall/PIM\%20Chapter-Marshall.pdf.

This is the accepted version of the following article: Copeland, A. J. (2011). Analysis of public library users' digital preservation practices. Journal of the American Society for Information Science and Technology, 62(7), 1288-1300, which has been published in final form at http://dx.doi.org/10.1002/asi.21553 
Marshall, C. (2008a). Rethinking personal digital archiving part 2. D-Lib Magazine, 14(3/4).

Marshall, C. (2008b). Rethinking personal digital archiving part 1. D-Lib Magazine, $14(3 / 4)$

Marshall, C., Bly, S., \& Brun-Cottan, F. (2006). The long term fate of our digital belongings:

Towards a service model for personal archives. In Proceedings of

IS\&T Archiving 2006, Ottawa, Canada, May 23-26, 2006. Springfield, VA:

Society for Imaging Science and Technology, pp. 25-30.

Mellon, C. (1986). Library anxiety: A grounded theory and its development. College \& Research Libraries, 47, 160-165.

Nahl, D. \& Bilal, eds. (2007). Information and Emotion. Medford, NJ: Information Today.

National Diet Library of Japan. (2008). Ensuring long-term preservation and usability of digital information. Retrieved from http://www.ndl.go.jp/en/aboutus/preservation.html.

PARADIGM. (2008). Workbook on digital Private Papers. Retrieved from http://www.paradigm.ac.uk/workbook/index.html.

Porck, H. \& Teygeler, R. (2000, December). Preservation Science Survey. Retrieved from http://www.clir.org/pubs/reports/pub95/contents.html.

Rodden, K. \& Wood K. (2003). How do people manage their digital photographs? CHI 2003. April 5-10, 2003. Ft. Lauderdale, Florida, USA.

This is the accepted version of the following article: Copeland, A. J. (2011). Analysis of public library users' digital preservation practices. Journal of the American Society for Information Science and Technology, 62(7), 1288-1300, which has been published in final form at http://dx.doi.org/10.1002/asi.21553 
Ross, S. \& Hedstrom, M. (2005). Preservation research and sustainable digital libraries. International Journal on Digital Libraries, (5), 317-324.

Rothenberg, J. (1998). Avoiding technological quicksand: Finding a viable technical foundation for digital preservation. A Report from the Council on Library and Information Resources. Retrieved from http://www.clir.org/PUBS/reports/rothenberg/contents.html.

Savolainen, R. (1995). Everyday life information seeking: approaching information seeking in the context of 'Way of Life.' LISR, 17 (3), 259-294.

Savolainen, R. (2006). Time as context of information seeking. LISR, 28, 110-127.

Savolainen, R. (2007). Information source horizons and source preferences of environmental activists: A social phenomenological approach. JASIS\&T, 58(12), 1709-1719.

Savolainen, R. (2008). Source preferences in the context of seeking problem-specific information. Information Processing and Manage, 44(1), 274-293.

Savolainen, R. \& Kari, J. (2004). Placing the internet in information source horizons. A study of Information seeking by internet users in the context of self-development. LISR, 26, 415433.

Schamber, L. (1996). What is a document? Rethinking the concept in uneasy times. JASIS, 47(9), 669-671.

Sonnenwald, D. H. (1999). Evolving the perspectives of human information behavior: Contexts, situations, social networks and information horizons. In T. Wilson \& D. Allen (Eds.), Exploring the Contexts of Information Behavior (pp. 176-190).

This is the accepted version of the following article: Copeland, A. J. (2011). Analysis of public library users' digital preservation practices. Journal of the American Society for Information Science and Technology, 62(7), 1288-1300, which has been published in final form at http://dx.doi.org/10.1002/asi.21553 
Sonnenwald, D. H. \& Wildemuth, B. M. (2001). A research method to investigate information seeking using the concept of information horizons: an example form a study of lower socio-economic students' information seeking behavior. The New Review of Information Behavior Research, 2, 65-86.

Tang, R. \& Solomon, P. (1998). Toward an understanding of the dynamics of relevance judgment: An analysis of one person's search behavior. Information Processing \& Management, 34(2-3), 237-256.

Teevan, J., et al. (2004). The perfect search engine is not enough: A study of orienteering behavior in directed search. Conference on Human Factors in Computing Systems (pp. 415-22). New York, NY: ACM.

Tenopir, C., Wang, P., Zhang, Y., Simmons, B., \& Pollard, R. (2008). Academic users' interactions with ScienceDirect in search tasks: Affective and cognitive behaviors. Information Processing \& Management, 44(1), 105-121.

Whittaker, S. (2010). Personal information management: From information consumption to curation. ARIST. [In Press].

Whittaker, S. \& Sidner, C. (1996). Email overload: exploring personal information Management of email. CHI 96. April 13-18, 1996, Vancouver, BC, Canada. Whittaker, S. \& Hirschberg, J. (2001). The character, value, and management of 
personal paper archives. ACM Transactions on Computer-Human

Interaction, 8(2), 150-170.

Whittaker, S., Bellottti, V., \& Gwizdka, J. (2006). Email in personal information management. Communications of the ACM, 49(1), 68-73.

Wurman, R. (1989). Information Anxiety. New York: Doubleday.

Wurman, R., Sume, D. \& Loring, L. (2000). Information Anxiety 2. Que.

Yakel, E. (2004, October). Seeking Information, seeking connections, seeking meaning: genealogists and family historians. Information Research, 10(1). Retrieved from http://informationr.net/ir/10-1/paper205.html .

Xu, Y. \& Chen Z. (2006). Relevance judgment: What do information users consider beyond topicality? JASIS\&T, 57(7), 961-973.

Zach, L. (2006). Using multiple-case studies design to investigate the information seeking behavior of arts administrators. Research Methods, 55(1), 4-21.

This is the accepted version of the following article: Copeland, A. J. (2011). Analysis of public library users' digital preservation practices. Journal of the American Society for Information Science and Technology, 62(7), 1288-1300, which has been published in final form at http://dx.doi.org/10.1002/asi.21553 